\title{
Electrochemical Chloride Extraction From Corrosion-Resistant Steel Bar-Reinforced Concrete
}

\author{
Du Fengyin, Jin Zuquan",Zhao Tiejun, Dai Xueyan \\ College of Civil Engineering, Qingdao University of Technology, Qingdao, China \\ *E-mail: jinzuquan@126.com
}

doi: $10.20964 / 2018.07 .79$

Received: 10 March 2018 / Accepted: 18 April 2018 / Published: 5 June 2018

Chloride ion-contaminated concretes with low-carbon steel bar (LC) and corrosion-resistant steel bars (CR) were studied by electrochemical chloride extraction (ECE). The efficiency of the ECE treatment with different electrolyte solutions, current density, protective cover thickness and concrete type were investigated. Moreover, the microstructures, elements distribution, calcium hydroxide content of the concrete, and the interface zone between steel bars and concrete were observed. When ECE treatment with stainless mesh as the anode was applied in contaminated reinforced concrete, the experimental results indicated that a current density of $2 \mathrm{~A} / \mathrm{m}^{2}$ and a $\mathrm{Ca}(\mathrm{OH})_{2}$ solution are recommended. Increasing the concrete cover and compactness of the reinforced concrete decreased the chloride ion removal efficiency. The differences among the steel bar types on the concrete ECE treatment efficiency was negligible. After ECE treatment, re-passivation of steel bars could occur due to the $\mathrm{pH}$ recovery and dense microstructure induced by ECE treatment.

Keywords: reinforced concrete; electrochemical chloride extraction; corrosion-resistant steel bar; microstructure

\section{$\underline{\text { FULL TEXT }}$}

(C) 2018 The Authors. Published by ESG (www.electrochemsci.org). This article is an open access article distributed under the terms and conditions of the Creative Commons Attribution license (http://creativecommons.org/licenses/by/4.0/). 